\title{
QUESTÕES, PROPOSIÇÕES, ARTICULAÇÕES: Um Panorama Analítico do I Seminário da Rede de Estudos Contemporâneos da Baixada Fluminense
}

\author{
André Santos da Rocha \\ Doutor em Geografia pela UFRJ; Professor da UFRRJ, asrgeo@gmail.com \\ Leandro Dias de Oliveira \\ Doutor em Geografia pela UNICAMP; Professor da UFRRJ, Idiasufrrj@gmail.com \\ Sidney Cardoso Santos Filho \\ Mestre em Geografia pela UERJ- Maracanã; Pesquisador do REC-LAGEPPE/UFRRJ. \\ sidgeo@hotmail.com
}

\section{RESUMO}

A Baixada Fluminense, área integrante da Região Metropolitana do Rio de janeiro e conhecida popularmente pela representação de pobreza e altos índices de violência e baixos indicadores sociais, passou por profundas transformações. Estas incluem desde questões na esfera política marcada pelas emancipações nos anos de 1990 e consequente redinamização eleitoral até $\mathrm{o}$ aparecimento de novos investimentos na região, seja no setor imobiliário, seja no industrial. Igualmente, não se deve ignorar as dinâmicas culturais que se expandem via criação de grupos de dança, música, teatro, entre outros, até a consolidação de instituições de pesquisa sobre a história da região, cujas ações reverberam no pulsar sócio-político da Baixada. Este artigo buscou apresentar os principais eixos das inquietações que animaram o I Seminário da Rede de Estudos Contemporâneos da Baixada Fluminense.

Palavras-chave: Baixada Fluminense, pesquisa, história

\section{RÉSUMÉ}

Le Baixada Fluminense, une partie de larégionmétropolitaine de Rio de Janeiro et populairementconnu par lareprésentation de lapauvreté et destauxélevés de violence et de faiblesindicateurssociaux, a subi de profondschangements. Ellesvont de 
problèmesdanslasphère politique marquée par l'émancipationdanslesannées 1990 et l'électionconsécutive de revitalisation à l'émergence de nouveaux investissementsdanslarégion, que cesoitdansbranchel'immobilier, que cesoitdansl'industrie. Aussi, il ne fautpasignorerlesdynamiquesculturellesquiaugmententaveclacréation de groupes de danse, musique, théâtre, entre autres, à laconsolidationdesinstitutions de recherchesurl'histoire de larégion, dontlesactions se répercutentdansl'impulsionsocio-politique de la Baixada. Cedocument vise à présenterlesprincipauxdomaines de préoccupationsquiontaniméle I Seminário da Rede de Estudos Contemporâneos da Baixada Fluminense.

Mots-clés: Baixada Fluminense, recherche, histoire Introdução

A Baixada Fluminense, área integrante da Região Metropolitana do Rio de janeiro e conhecida popularmente pela representação de pobreza e altos índices de violência e baixos indicadores sociais, passou por profundas transformações. Estas incluem desde questões na esfera política marcada pelas emancipações nos anos de 1990 e consequente redinamização eleitoral até o aparecimento de novos investimentos na região, seja no setor imobiliário, seja no industrial. Igualmente, não se deve ignorar as dinâmicas culturais que se expandem via criação de grupos de dança, música, teatro, entre outros, até a consolidação de instituições de pesquisa sobre a história da região, cujas ações reverberam no pulsar sócio-político da Baixada. A Baixada Fluminense, bem como a Região Metropolitana e o próprio estado do Rio de Janeiro como um todo, assistem um novo ciclo de desenvolvimento econômico (OLIVERA, 2008; SILVA, 2012) que merece ser melhor avaliado.

Ao mesmo tempo em que a Baixada se reformula economicamente, se verificou a consolidação e expansão de centros de educação superior na região e a concomitante emersão de pesquisadores que incorporaram a problematização de questões desta área em suas agendas. Todavia, percebese a necessidade de articulação destas iniciativas com a finalidade de reunir as contribuições de pesquisas sobre essa Baixada contemporânea e também de construção de pautas de proposição para questões e demandas regionais respeitandoas singularidades municipais. 
A multiplicidade dos fenômenos sociais, políticos e econômicos que se desencadeiam na Baixada, revelam por si a amplitude das questões das quais diferentes campos de conhecimento - como a Geografia, a História, a Sociologia, a Antropologia, a Literatura, entre outras - que, a partir de seus preceitos e métodos, podem contribuir para a compreensão e alargamento do conhecimento. Este encontro de saberes acerca da Baixada Fluminense vislumbra: [a] a popularização da história e dos fenômenos sociais locais regionais; [b] a aproximação de pesquisas de forma complementar e sistemática; [c] a disseminação de práticas pedagógicas para melhorias da educação básica na região; [d] a sistematização de informações importantes para tecer, por exemplo, políticas públicas de forma horizontalizada.

Neste sentido, este primeiro seminário - organizado pelos professores André Santos da Rocha (coordenador-geral), Leandro Dias de Oliveira e Sidney Cardoso -, teve como objetivo central articular e apresentar questões e também reunir proposições que balizassem ações coletivas de estudos contemporâneos na Baixada. Assim, pesquisadores, gestores públicos, estudantes e professores das redes pública e privada foram convidados para conhecer e solidificar os interesses desta rede embrionária. Realizado entre os dias 18 e 19 de novembro no Auditório Paulo Freire (ICHS-UFRRJSeropédica), o I Seminário da Rede de Estudos Contemporâneos da Baixada Fluminense atingiu o seu maior objetivo: proporcionar o encontro entre ideais de pesquisadores que tem na Baixada Fluminense um verdadeiro desafio político e intelectual.

Este seminário foi constituído por duas mesas de debate: [I] Estudos e conhecimentos sobre a Baixada Fluminense, realizada no dia 18 de novembro; e [II] Questões contemporâneas sobre a Baixada Fluminense: violência, política e desenvolvimento, que ocorreu no dia seguinte (19 de novembro). São exatamente sobre os tensionamentos analíticos desenvolvidos nestes dois momentos que nos debruçaremos a seguir.

\section{I - Estudose conhecimentossobre a Baixada Fluminense}


O primeiro dia do evento, iniciado na manhã de 18 de novembro de 2014, foi dividido em dois momentos: apresentação do evento com presença de representantes da Universidade Federal Rural do Rio de Janeiro (UFRRJ) e o debate com a mesa de discussão - Estudos e conhecimentos sobre a Baixada Fluminense.

$\mathrm{Na}$ abertura do evento foi destacada a iniciativa de reunir pesquisadores e apresentar as temáticas de estudos, bem como da possibilidade de dialogar com os diferentes grupos reunidos. Além da comissão organizadora, esse momento contou com a participação da profa. Andrea Sampaio - Chefe do Departamento de Geociências(DEGEO) - e do Prof. Alexis Nummer - Diretor do Instituto de Agronomia (IA). Ambos ratificaram a importância da realização do evento para Universidade, que situada na Baixada Fluminense - com campus em Seropédica e Nova Iguaçu - necessita dialogar com mais intensidade com realidade local, a partir de iniciativas que fomentem e articulem a pesquisa, ensino e extensão. Outrossim, indicou-se o papel que área de Geografia possui, na figura dos professores organizadores, em articular juntamente com professores dos demais institutos da Universidade como ICHS e IM - vias conjuntas que fortaleçam campos de estudos contemporâneos nas áreas de Geociências e Humanidades.

Em seguida, deu-se início a Mesa: Estudos e conhecimentos sobre a Baixada Fluminense, que contou com a participação das professoras Simone Fadel e Maria de Fatima Paiva (UERJ- FEBF), Lucia Helena Pereira da Silva (IM-UFRRJ); Tania Amaro (UNIGRANRIO e Instituto Histórico de Duque de Caxias); e dos professores Manoel Ricardo Simões (IFRJ) e Leandro Dias de Oliveira (DEGEO-UFRRJ), sendo este último o mediador da Mesa.

Simone Fadel, professora do Curso de Geografia da Universidade do Estado do Rio de Janeiro na Faculdade de Educação da Baixada Fluminense (UERJ-FEBF), autora da obra "Meio Ambiente, Saneamento e Engenharia no Império e na República", que discute a história ambiental e do saneamento na região, explora em sua apresentação a importância da reunião de informações para práticas pedagógicas mais amplas no contexto da Baixada. 
Ao apresentar seu núcleo de trabalho NIESBF - Núcleo Interdisciplinar de estudos do Espaço da Baixada Fluminense - destaca as múltiplas perspectivas de estudos de seu grupo que conta com participação de outros professores do curso de geografia da UERJ-FEBF, mostrando pesquisas que tranversalizam temas como compreensão do espaço urbano; história e meio ambiente, políticas públicas, trabalho e história regional.Uma das ações do grupo que tem como frente de trabalho reunir e expor informações ambientais da região em formato virtual é externado na consolidação e alimentação daBiblioteca Virtual de Meio ambiente da Baixada Fluminense ${ }^{1}$

Simone Fadel dá destaque às iniciativas de extensão com políticas de educação ambiental nas escolas públicas da região. Lembrando a complexidade biogeomorfológica que contempla a região, por exemplo mangues, resquícios de mata atlântica. Urge em sua fala a questão da preservação do patrimônio natural, que perpassa além das práticas de educação ambiental, as políticas de gestão territorial dos municípios. Inclusive foi mencionada a criação do Mosaico Central Fluminense, proposta pela ACMbioque visa a gestão integrada da área de conservação ambiental que cercam o domínio da Mata Atlântica, que passa por muitas áreas da Baixadaáreas que são tensionadas gradativamente com a incorporação e expansão urbana e da nova dinâmica econômica que pode levar a perda gradativa de áreas de conversação - vide as perdas ocorridas com a abertura do Arco metropolitano ${ }^{2}$.

Complementar a fala de Simone Fadel, Maria de Fatima Paiva apresenta as iniciativas do PIMBA (Programa de Integrado de Pesquisa e Cooperação Técnica na Baixada Fluminense) que se revela uma importante ação conjunta de ações de extensão, também num caráter multidisciplinar, vem acompanhado diversas ações para o fomento acadêmico e social na região,

\footnotetext{
${ }^{1}$ Disponível em http://www.bvambientebf.ueri.br/

2 Veja reportagem do jornal do Comercio, intitulada "Nó ambiental atrasa o Arco Metropolitano". Disponível em :<http://iconline.ne10.uol.com.br/canal/economia/pernambuco/noticia/2014/04/17/noambiental-atrasa-o-arco-metropolitano-125350.php.>. Data do Acesso: 25/11/2014.
} 
abrindo o convite para todos os colegas a participarem da proposta do programa.

Em seguida, Lucia Helena Pereira da Silva, professora do Instituto Multidisciplinar (IM) e do Programa de Pós-Graduação em Desenvolvimento Territorial e políticas Públicas (PPGDT) da UFRRJ, destaca que não é possível pensar estudos e conhecimentos sobre a Baixada, sem se debruçar sobre a singular história territorial da região.

Neste sentido, Lucia Silva, destaca que a própria história do Saneamento está ligada ao que conhecemos hoje como Baixada, até porque esta nomenclatura não fora usada antes das efetivas ações de estudos sobre o saneamento, como as realizadas por engenheiro Hildebrando de Goés. Nesta perspectiva, as "políticas oficiais" são lembradas, destacando que a Baixada que conhecemos hoje - urbana e associada dinâmica da metrópole -foi impulsionada e legitimada pós 1970 com a criação da FUNDREM - Fundação para o Desenvolvimento da Região Metropolitana do Rio de Janeiro. É ressaltada uma possível associação entre a norma jurídica que funda esta entidade com as políticas de planejamento da Região Metropolitana e consequentemente para sua periferia - a Baixada Fluminense.

A seguir, Tania Amaro, professora do curso de História da Unigranrio e Diretora responsável do Instituto Histórico de Duque de Caxias, destaca em sua fala que "o conhecimento e o estudo sobre a Baixada Fluminense" passa por um desafio hercúleo: preservar história e o patrimônio regional em detrimento às lógicas diversas.

Em primeiro lugar, construir um consenso sobre a ideia de patrimônio coletivo, embora pareça de fácil conciliação - tendo em vista uma materialização cultural-histórica nas paisagens dos municípios a partir de formas como igrejas, casarões, pontos ferroviários, entre outras formas - isto se revela de difícil diálogo com representantes políticos ou mesmo proprietários privados. Estes permitem o definhar das estruturas físicas de patrimônios histórico-culturais por desconhecimento, falta de técnicas de preservação ou mesmo por necessidade de supressão destas formas - seja para novos usos, que alteram significativamente fachadas e estruturas internas de prédios 
históricos, seja pela liquidação total da forma, para dar caboaos novos empreendimentos.

Um exemplo citado foi o da Igreja do Pilar - Igreja de estilo Barroco localizado no bairro do Pilarem Duque de Caxias - que hoje passa por grandes problemas de estrutura por falta de conservação adequada. Outrossim, não se pode ignorar o desafio de construir significados sobre aquilo que chamamos de História e seu patrimônio com a realidade dos moradores locais. Foi levantado como exemplo a desconhecimento de parte da população de Duque de Caxias sobre a Estátua daquele que é homenageado com o nome da cidade - muitos atribuem à figura de São Jorge Guerreiro a referida estátua!Eis uma questão que referenda as dificuldades de construção de um imaginário histórico coletivo na Baixada Fluminense.

Manoel Ricardo Simões, geógrafo professor do Instituto Federal do Rio de Janeiro (IFRJ - campus Nilópolis), pesquisador da Baixada Fluminense, que se consolida como referência introdutória aos estudos regionais, sobretudo por suas duas obras: "A cidade estilhaçada: reestruturação econômica e emancipações municipais na Baixada Fluminense" (2007); e "Ambiente e Sociedade na Baixada Fluminense" (2011), apresenta pontos fundantes para compreensão da Baixada Fluminense, tomando exatamente a construção de suas obras.

Em primeiro lugar, no contexto da mesa, Manoel Simões, destaca que suas principais obras são produtos tanto da vivência quanto dos estudos sobre a região que já alcançam mais de trinta anos, sobretudo a partir do aprofundamento teórico nos cursos de graduação, mestrado e Doutorado. Em seguida, argumenta sobre a importância do papel investigativo da leitura de trabalhos pontuais - teórico e empíricos - que foram construídos sobre a Baixada de que opesquisador se alimentou para dar corpo a seu último livro.

Abre-se em sua fala dimensão geral que compreende hoje a Baixada, seja em seu caráter regional (entre o núcleo e sua expansão) seja nos processos particulares por que passam os municípios, mostrando que processos gerais se reproduzem com especificidades. 
Neste contexto, Manoel Simões exemplifica o núcleo central de Nova Iguaçu ao apresentar a questão de uma cidade que se mostra "partida" no seu processo de crescimento urbano - para o autor dividida em três partes: centro - área localizada entre a linha férrea e via Light que se caracterizada pelo forte setor terciário de comércio popular; o "Outro lado" - área localizada entre o maciço e a linha férrea que se caracteriza hoje pela forte especulação imobiliária e uma respectiva verticalização, e de consolidação de um conteúdo social mais abastado; e o que chama de "terceiro centro" - localizada entre a Via Ligtha qualatribui a expansão das atividades terciárias que expandem as atividades do centro.

Manoel Simões deixa claro que hoje Nova Iguaçu vivencia as vicissitudes da cidade contemporânea: verticalização; especulação imobiliária; políticas de segregação; problemas de mobilidade. Fica evidente que as novas dinâmicas econômicas em curso na região metropolitana, inserem Nova Iguaçu num contexto de reestruturação territorial produtiva, que nos impulsiona a abandonar as velhas alusões de cidades-dormitório, tão estigmatizadas e associadas à Baixada Fluminense.

Após as falas dos componentes da mesa, Leandro Dias de Oliveira - na figura de mediador do debate abre às reflexões sinalizando às complexidades que transversalizam os estudos sobre a Baixada, seja na perceptiva da patrimonialização ambiental e histórica; seja na nova interpretação regional e territorial da Baixada diante dos imperativos do atual modelo de acumulação.

Tomando cabo desta reflexão, o professor Edson Miagusko, professor do Departamento de Ciências Sociais do ICHS - UFRRJ, argumenta a importância de visualizar as representações e a construção da imagem de Baixada que podem servir de obstáculo aos novos estudos, por mais que se busquem fontes históricas de "fundação" da ideia de Baixada.

Em seguida, professor Marcio Rufino (DEGEO), destaca a percepção da distinção tanto interna dos municípios quanto entre diferentes localidades na metrópole, como parte da experiência dos sujeitos. Esta não é apenas singular à Baixada e é comum em outras metrópoles como São Paulo. O "ir à cidade", seja ir do bairro de Miguel Couto ao Centro de Nova Iguaçu ou ir de Japeri ao 
centro da cidade do Rio, são mobilidades internas que traduzem conteúdos sociais e econômicos que afetam o imaginário do ato de experimentar a cidade - por mais integrada que ela seja.

Em seguida, Gabriel Menezes - Bacharel em Geografia pela UFRRJ, faz um comentário sobre o papel das ferrovias na construção do imaginário pertencente a Baixada, uma vez que a linha férrea marca a centralidade da maioria dos municípios e serve de conexão de transporte de pessoas entre diferentes localidades com a metrópole carioca.

\section{II - Questões contemporâneas sobre a Baixada Fluminense: violência, política e desenvolvimento}

A segunda mesa, que ocorreu na manhã de 19 de novembro de 2014, reuniu professores da Universidade Federal Rural do Rio de Janeiro: José Claudio Souza Alves (ICHS), André Santos da Rocha, Regina Cohen Barros e Leandro Dias de Oliveira (todos do DEGEO) - este último como mediador - e teve como tema central: "Questões contemporâneas sobre a Baixada Fluminense: violência, política e desenvolvimento".

Assim, José Cláudio Souza Alves, professor do Instituto de Ciências Humanas e Sociais da UFRRJ - Universidade Federal Rural do Rio de Janeiro e autor da obra "Dos barões ao extermínio: uma história da violência na Baixada Fluminense" (2003)[já tornada um clássico sobre a Baixada!], com larga experiência em estudos acerca da violência praticada nesta região, pode, de antemão, explorar o espraiamento da criminalidade organizada para além das fronteiras da cidade do Rio de Janeiro. José Cláudio Souza Alves apresentou números, dados e informações contundentes, que revelam 0 quanto a explosão de violência que assistimos cotidianamente é fruto de uma espiral explicativa, que perpassa a política, a economia e a própria civilidade capitalista. 
Em sua apresentação, mostrou a ocorrência da "faccionalização do crime", ou seja, a travessia da fronteira entre ações criminosas esporádicas, desarticuladas e com espectro mais local, para um massivo conjunto de violência em rede, calcado no empresariamento do "mundo da droga", na configuração territorial alicerçada em comandos hierarquizados e na constituição de uma rede muito bem dirigida e com evidentes veios de poder com laços viscerais com o mundo legal - Estado, capital, política e polícia. O combate a este novo criminoso, mais fragilizado em relação à cadeia de poder estabelecida, se dá por meio da "milicialização da polícia", agora com licença para matar em nome da paz que mais ninguém acredita.

Não se permitia dúvidas em sua fala: esta violência é conjuntural, e não difere da praticada pelo juiz no recente e repugnante caso em que o mesmo processou a agente de trânsito por cumprir o seu dever ${ }^{3}$. Vivemos em uma sociedade calcada na força, aceitamos a violência com o outro e não raro praticamos atos - no trânsito, no trabalho, na vida! - que estão preenchidos por uma carga simbólica de bestialidade e brutalidade. A nossa sociedade é violenta, e está devidamente anabolizada pelos desmandos do Estado e do capital em suas múltiplas formas. $O$ traficante não é o oposto da civilização, mas a sua coroação sem máscaras ou camuflagens.

A seguir, André Santos da Rocha apontou as múltiplas representações em curso a respeito da Baixada Fluminense. Professor do Departamento de Geociências da UFRRJ e autor de vários trabalhos sobre o tema, André Rocha pode mostrar os artifícios ideológicos a respeito do que é ser, pertencer e viver na Baixada, que se transforma cotidianamente de forma visível a olho nu e cujas contradições são exploradas de acordo com os interesses e prioridades.

Afinal, o que é a Baixada hoje? Como se não bastassem as mutações históricas - factuais e conceituais - deste recorte regional, nas últimas décadas a Baixada Fluminense vem experimentando fortes modificações em sua

\footnotetext{
${ }^{3}$ Referência ao casodo juiz João Carlos de Souza Correa, que conseguiu processar por danos morais a agente da operação Luciana Silva Tamburini, cujo "crime" foi abordar um juiz em uma blitz da Lei Seca na Zona Sul do Rio. Vale asseverar: o juiz João Carlos conduzia um Land Rover sem placas e não portava carteira de habilitação.Afinal, o que pode ser mais violento que o uso da força por via legal para recriminar quem quer manter a ordem? Ver: http://g1.globo.com/rio-dejaneiro/noticia/2014/11/justica-do-ri-manda-agente-da-lei-seca-indenizar-juiz-abordado-sem-cnh.html. Acesso em: 22 de novembro de 2014.
} 
estrutura econômica, que envolve o aparecimento de novos investimentos e / ou incremento de antigas bases produtivas. Vem ocorrendo uma verdadeira reestruturação territorial-produtiva desta área, fazendo com que a Baixada estigmatizada pela violência urbana coabitasse o imaginário coletivo como um lugar promissor para os mais diversos investimentos, do ramo hoteleiroimobiliário ao técnico-industrial.

Assim, ora a Baixada Fluminense é o epicentro da pobreza do estado do Rio de Janeiro, que exigem investimentos constantes para a supressão dos maiores males sociais existentes, ora a região é o espaço luminoso do desenvolvimento estadual, fruto de uma revolução logística - particularmente, com a construção do Arco Rodoviário Metropolitano que emerge como símbolo máximo desta nova qualidade regional (GOMES FILHO, 2014; ROCHA, OLIVEIRA, 2010) - industrial, econômica, social e instrucional. Com novos e luxuosos prédios, rede de serviços sofisticados, inauguração de centros de ensino nos mais diversos níveis, a Baixada Fluminense segue nesta proposital dialética de "área pobre - região promissora".

Regina Cohen Barros, professora do Departamento de Geociências da UFRRJ e com larga experiência em estudos agrários, trouxe para a ágora um tema deveras oportuno: a geografia agrícola da Baixada Fluminense em tempos de reestruturação territorial-produtiva. Através dos estudos acerca dos casos de Queimados e Seropédica, que são cidades que assistem uma reestruturaçãoterritorial-produtiva (MORAIS, 2014; OLIVEIRA et. al. 2014a) Regina Barros também articulou suas análises, metodologicamente, com a Zona Oeste Carioca, por meio do exemplo do bairro de Campo Grande - foi possível notar que há novas conformações agrícolas nestes municípios, particularmente em casos de agricultura orgânica e familiar.

Assim, em sua fala ficou patente: o aumento de número de feiras de produtos orgânicos nestas cidades; a dura resistência deste pequeno produtor que compete com os novos fluxos empresariais e de poder; o desconhecimento - quando não a solene ignorância - acerca da importância da produção familiar no abastecimento de alimentos para a região; a falta de investimentos públicos neste artífice da agricultura; a própria mudança na concepção de mundo rural. 
A rigor, Regina Barros pode aludir um tratamento de fundo teórico: não é possível falarmos - tendo como base a Região Metropolitana Fluminense e os municípios estudados - em áreas estritamente rurais; hoje, assistimos a consolidação de um continuum rural-urbano, intercalado, interdependente e indissociável. O rural está presente nos interstícios da escala urbana, mas não como atividade de fendas espaciais da mancha metropolitana e sim como uma complexidade do mundo contemporâneo que insiste em dificultar classificações históricas. Afinal, o que é rural hoje?

$O$ debate subsequente trouxe questões importantes para reflexão: Marcio Rufino, professor do DEGEO-UFRRJ, manifestou o sentimento de letargia e consternação da população perante as dificuldades em enfrentar a violência urbana, e aproximou este debate da realidade paulista, mostrando o quanto se trata de uma questão estrutural; Everaldo Lisboa, pesquisador da Baixada Fluminense, discorreu, cobrando posições teóricas junto aos componentes da mesa, sobre as mudanças em curso na Baixada Fluminense, apontando a elitização do Centro de Nova Iguaçu, por exemplo; Guilherme Chalo, graduando do curso de Geografia do DEGEO-UFRRJ, acenou para os contatos em diferentes escalas do desenvolvimento da Baixada, particularmente nas escalas global, nacional e metropolitana; neste sentido, Leandro Dias de Oliveira, mediador da mesa, inquiriu a respeito do anúncio da Supersecretaria da Região Metropolitana do Rio de Janeiro ${ }^{4}$, que poderá trazer consigo novas formas de combate à faccionalização do crime para além da capital fluminense, redinamizar as centralidades da Baixada -uma vez que a reestruturação territorial-produtiva (OLIVEIRA, 2014; OLIVEIRA et. al. 2014) tem efetivamente constituído novas centralidades para além de Nova Iguaçu e Duque de Caxias - e ainda proporcionar até mesmo a consolidação de uma agricultura urbana, com implantação de planos diretores coerentes com as necessidades local-regionais. São questões contemporâneas, que somente reforçam a noção de que novas agendas de pesquisa surgem no horizonte teórico-acadêmico da Baixada Fluminense.

\footnotetext{
${ }^{4}$ Ver: http://g1.globo.com/rio-de-janeiro/noticia/2014/10/pezao-quer-apoio-da-uniao-na-segurancadas-rodovias-federais.html.
} 


\section{III - Questões, Proposições, Articulações: Novas agendas de pesquisa e de ação}

Este seminário sobre a Baixada Fluminense, mostrou, o caráter plural de temas e de caminhos investigativos. Essa região se consolida na contemporaneidade como um importante objeto de análise, independente das filiação teórica e política e para além das amarras científicas de um único campo. Os processos que produzem o espaço e as relações econômicas e políticas na Baixada, precisam ser interpretadas à luz da geografia, mas também da história, da filosofia, das ciências sociais e das humanidades. É necessário humanizar, desnaturalizar e politizar as perspectivas de estudos regionais. Neste sentido, apontam-se demandas investigativas, a saber:

[1] estudos sobre patrimônio ambiental e histórico regional - ao mesmo tempo em quesurgem desafios à preservação da paisagem na região, demandam-se agora novas perspectivas de identificação e inventário da paisagem e consequentemente daquilo que se entende como patrimônio cultural/histórico e ambiental. Assim, há carência de estudos queenvolvem a catalogaçãodas formas históricas das antigas vilas e freguesias de Iguassú e Estrela, mas também da Baixada moderna sobretudo dos marcos da primeira metade do século $\mathrm{XX}$, por exemplo oriundo do ciclo da Laranja; dinamização das políticas de preservação e construção de referências coletivas; identificação de grupos e agentes sociais envolvidos em lutas sobre o patrimônio ambiental e histórico.

[2] Questões urbano-regionais no âmago da restruturação territorial produtiva, mediante a criação e consolidação de distritos industriais em praticamente todas as cidades - Nova Iguaçu, Paracambi, Seropédica, Queimados, Japeri etc. - , instalação de portos-secos e retroportos, parques logísticos, empresas produtoras de maquinários, observáveis em praticamente todos os entroncamentos rodoviários: Via Dutra, Reta de Piranema, BR-465 
(Antiga Estrada Rio-São Paulo), Via Light, para ficar somente nos principais exemplos. O Arco Rodoviário Metropolitano já se consolidou como agenda de pesquisa: todo aquele que pensa a região e o papel das conexões entre espaços já detectou a importância estratégica desta nova rodovia e começa a avaliar os impactos futuros.

[3] Agentes, representações e apropriação do território-a questão territorial é patente quanto observado as estratégias de agentes e grupos que têm na região seu foco de atuação. A dinâmica de violência, grupos milicianos e o próprio tráfico introduzem em diferentes bairros novas lógicas territoriais. Não se pode ignorar os territórios políticos estratégicos na garantia de votos bem como de agentes econômicos como a Firjan que atuam em defesa da delimitação de áreas próprias à nova dinâmica fabril. Também, é necessário identificar e analisar o papel dos movimentos sociais de resistência que atuam de forma territorializadaque, por vezes, sofrem de forma mais dura as vias do desenvolvimento regional

[4] Singularidades e similitudes do continuum rural-urbano dos municípioscomponentes da Baixada Fluminense, uma região historicamente vinculada a tradições agrícolas e que hoje assiste um processo inequívoco de supressão do espaço rural pela expansão da mancha urbana. Se a expansão urbano-metropolitana parece incorporar antigas áreas rurais, os produtores familiares de Paracambi, Seropédica ou Queimados, as atividades de turismo rural em Xerém ou Tinguá e as próprias áreas destinadas à pecuária ainda existentes nas bordas da área metropolitana necessitam de uma análise profícua. O que é rural na Baixada hoje? E o urbano permite ser elastificado conceitualmente e incorporar produções típicas do campo? E as relações, interfaces e circuitos campo-cidade: como classificar atualmente estafronteira tão tênue quanto móvel? São desafios analíticos que requerem atenção dos pesquisadores, presentes e futuros.

\section{Referências Bibliográficas:}


ALVES, José Cláudio Souza. Dos Barões ao Extermínio uma história de violência na Baixada Fluminense. Rio de Janeiro, APPH-Clio, 2003.

GOMES FILHO, Júlio César. O Arco Rodoviário Metropolitano como Elemento de Reestruturação do Espaço Fluminense. Continentes: Revista de Geografia do Depto. de Geociências da UFRRJ - Universidade Federal Rural do Rio de Janeiro. Revista Semestral - Ano 2, número 2, Jan. / Jun. 2013, p. 147-163. Disponível em:

http://r1.ufrri.br/revistaconti/index.php/continentes/article/view/16. Acesso em: 06 de novembro de 2014.

MORAIS, Marcelo Loura de. A Baixada Fluminense "Respira os Ares do Progresso": Um Estudo do Distrito Industrial de Queimados - RJ. Continentes: Revista de Geografia do Depto. de Geociências da UFRRJ- Universidade Federal Rural do Rio de Janeiro, ano 3, n. 4, Jan. / Jun. 2014, p. 154-179. Disponível em: http://r1.ufrri.br/revistaconti/index.php/continentes/article/view/44. Acesso em: 05 de novembro de 2014.

OLIVEIRA,Leandro Dias de.Geografia Urbana e Desenvolvimento Sustentável: Notas acerca da Reestruturação Espacial Contemporânea. In: OLIVEIRA, Floriano Godinho De; FREIRE, DésiréeGuichard, MASCARENHAS, Gilmar; OLIVEIRA,Leandro Dias de.(Orgs.). Geografia urbana: ciência e ação política. Rio deJaneiro: Editora Consequência, 2014.

OLIVEIRA,Leandro Dias de; HORTA, Ariane M. N. da; SOUSA, Lidiane S. de; CORDEIRO, Carla S. Seropédica: reestruturação produtiva e transformações espaciais. Pilares da História, ano 13, número 14, maio de 2014a.

OLIVEIRA,Leandro Dias de; MOURA,Ernane Fernandes; CHAGAS, Guilherme Mapelli; MORAIS, Marcelo Loura de. A Reestruturação Territorial-Produtiva Fluminense: Notas sobre Geografia da Indústria e Desenvolvimento 
Econômico. Continentes:Revista de Geografia do Depto. de Geociências da UFRRJ - Universidade Federal Rural do Rio de Janeiro, ano 3, n. 4, Jan. / Jun. 2014, p. 202-208. Disponível em: http://r1.ufrri.br/revistacont/index.php/continentes/article/view/46. Acesso em: 05 de novembro de 2014b.

OLIVEIRA, Floriano José Godinho de. Reestruturação produtiva, território e poder no estado do Rio de Janeiro. Rio de Janeiro: Editora Garamond, 2008.

ROCHA, André Santos da.As representações ideais de um território: Dinâmica econômica e política, agentes e a produção de novos sentidos na apropriação territorial da Baixada Fluminense pós-1990. Tese (Doutorado em Geografia) Instituto de Geociências, Universidade Federal do Rio de Janeiro, Rio de Janeiro, 2014.

ROCHA, André Santos da; OLIVEIRA, Leandro Dias de. As novas dinâmicas produtivas em curso na Baixada Fluminense: breves apontamentos sobre uma nova geografia da Indústria. Pilares da História. Ano 11, Edição Especial, p.713, maio de 2010.

SILVA, Robson Dias da. Indústria e Desenvolvimento Regional no Rio de Janeiro (1990-2008). Rio de Janeiro: Editora FGV [Faperj], 2012.

SIMÕES, Manoel Ricardo. A Cidade Estilhaçada:Reestruturação Econômica e Emancipações Municipais na Baixada Fluminense. Mesquita: Entorno, 2007. 